\title{
A territorialidade no contexto da criminalidade global: considerações sobre a influência do ciberespaço na delimitação jurisdicional
}

\author{
Territoriality in the context of global crime: reflections \\ of the impact of cyberspace on jurisdictional delimitation
}

\section{Daniel Leonhardt dos Santos ${ }^{1}$}

Pontifícia Universidade Católica do Rio Grande do Sul - Porto Alegre/RS daniel@leonhardtsantos.com

http://lattes.cnpq.br/7849499503476656

https://orcid.org/0000-0002-2954-5325

Resumo: O artigo desenvolve o problema estabelecido pelas novas tecnologias e o seu impacto para o direito, mais especificamente com a redução das distâncias e a facilitação de perpetração de condutas em territórios de múltiplos Estados. Problema cuja complexidade é ampliada pelo contexto de mundo global, de ampliação dos espaços de interação e de aproximação entre os indivíduos proporcionados pelo ciberespaço. O surgimento de novas tecnologias introduziu mudanças de necessário relevo à análise jurídica. Nesse contexto, buscamos responder à seguinte pergunta: as tradicionais categorias de territorialidade e de delimitação da jurisdição são suficientes para, no contexto internacional, resolver os complexos problemas introduzidos pela Internet? A partir da revisão bibliográfica sobre o tema, e do amparo de casos selecionados, concluímos que a territorialidade, amparada pela extraterritorialidade e pela delimitação da lei penal no espaço, não é suficiente para a solução desses problemas; encontrando-se, na

1 Doutor (2018) em Ciências Criminais pela Pontifícia Universidade Católica do Rio Grande do Sul com período de doutorado sanduíche (2017, PDSE-CAPES) na Faculdade de Direito da Universidade de Coimbra, Portugal. Mestre em Ciência Criminais pela Pontifícia Universidade Católica do Rio Grande do Sul (2014), especialista em Ciência Penais (2013) e Bacharel em Ciências Jurídicas e Sociais pela Pontifícia Universidade Católica do Rio Grande do Sul (2012). 
jurisdição prerrogativa, a principal barreira de atuação do poder estatal em âmbito internacional.

PalaVRas-chave: territorialidade; crimes transnacionais; jurisdição internacional.

AвSTRACT: The article elaborates on the problem established by new technologies and their impact on the law, more specifically with the narrowing of distances facilitating the perpetration of practices in territories of multiple states. A problem whose complexity is amplified by the context of the global world, of expanding the spaces of interaction and of approach between individuals provided by cyberspace. The emergence of new technologies introduced changes of necessary importance to legal analysis. In this context, we seek to answer the following question: are the traditional categories of territoriality and jurisdictional delimitation sufficient, in the international context, to solve the complex problems introduced by the Internet? From the bibliographic review on the subject, and the support of chosen cases, we conclude that territoriality, supported by extraterritoriality, is not enough to solve these problems; being, in the enforcement jurisdiction, the main barrier of action of state power in the international scope.

KEYWORDs: territoriality; transnational crimes; international jurisdiction.

SUMÁRIo: Introdução; 1 . As novas tecnologias e o seu impacto no direito penal no contexto global. Breve análise; 2 . O limite do tradicional princípio da territorialidade no contexto de criminalidade global; 3. O limite da jurisdição prerrogativa no âmbito online; Considerações finais; Referências.

\section{INTRODUÇÃO}

O direito penal possui um duplo aspecto de eficácia - positivo e negativo - ao qual, dentro desse âmbito, atrela-se um determinado território nacional pertencente a um determinado Estado. No seu aspecto de eficácia positivo, compete ao próprio Estado o julgamento e a punição de qualquer infração que, no bojo do seu território, é perpetrada. No seu aspecto de eficácia negativo - em uma simetria com o próprio âmbito positivo -, praticando, seus cidadãos, qualquer delito em outro espaço de 
eficácia de outro Estado, compete a este, então, a função de julgamento e punição dessa mesma conduta, e não ao Estado de origem do indivíduo.

Trata-se de uma arquitetura que resulta no princípio da territorialidade da aplicação da lei penal no espaço, com fundamento na soberania estatal. Essa é uma estrutura visível, conhecida e aceita, tendo em vista que o homem e seus comportamentos ocorrem, quaisquer que sejam eles, na sua representação social, em um determinado espaço. Ações que, antes do advento de muitos dos aparatos tecnológicos, possuem condutas e resultados atrelados a dimensões espaciais calculáveis e previsíveis. Havia uma visibilidade associada à conduta e ao resultado. Visibilidade que permitia delimitar cristalinamente o espaço ao qual essa conduta estava circunscrita. Nas palavras de Faria Costa, "tudo tinha lugar, tudo se passava, no território que era o 'lugar' da realização histórica de todos os lugares'”. ${ }^{2}$ Perspectiva que proporcionou a base gnosiológica do pensamento que estruturou todo o arcabouço teórico da aplicação da lei penal no espaço: na visibilidade e na previsibilidade dos espaços aos quais estão atreladas as condutas delitivas. Era uma relação consequencial clara e direta.

Em termos de Estado, essa relação ocorria pelo "dentro" e o "fora". O dentro do Estado - ao qual lhe competia julgar e punir - e o fora, ao qual lhe era estranho. Perspectiva que, com o advento dos aparatos tecnológicos e do mundo global, fragiliza-se, tornando-se insuficiente para a solução dos problemas impostos pelo crime transnacional. Não há mais o "dentro", nem o "fora”. ${ }^{3}$ As clássicas referências da aplicação da lei penal no espaço já não mais dão conta da complexidade das relações transnacionais e da ampliação dos espaços de interação desencadeados

2 FARIA COSTA, José de. Direito penal e globalização: reflexões não locais e pouco globais. Coimbra: Coimbra Editora, 2010, p. 72;75. Cf. os apontamentos apresentados em FARIA COSTA, José Francisco de. O princípio da territorialidade: entre Portugal e o Brasil. Revista de legislação e de jurisprudência, Coimbra, n. 3950, p. 285-293, 2008, p. 288 e ss.

3 Problemática que leva Faria Costa a afirmar: "o grande desafio deste século para o direito penal será o de reconstrução de toda a dogmática da aplicação da lei penal no espaço. Indubitavelmente" (FARIA COSTA, José Francisco de. O mundo de hoje e o direito penal: primeira aproximação. In: D'AVILA, Fabio Roberto; SANTOS, Daniel Leonhardt dos. Direito penal e política criminal. Porto Alegre: EDIPUCRS, 2016, p. 11). 
pelo desenvolvimento tecnológico, assim como as clássicas definições delimitadoras de um direito penal transnacional.

O trinômio estabelecido entre Estado soberano, território e jus puniendi, assentado na ideia de exclusividade, encontra-se, hoje, em crise. ${ }^{4}$ Dos vetores a ela associados - do fenômeno social ao jurídico-político -, Caeiro congrega a união de ambos como catalisadores dessa crise. De um lado, a representação social de certos fenômenos considerados globais, tais quais o terrorismo internacional ${ }^{5} \mathrm{e}$ o tráfico de armas nucleares, nos quais se exigem reações em uma mesma dimensão - i.e., reações globais -; assim como fatores outros como a ampliação da mobilidade internacional, dos fluxos migratórios e das violações aos direitos humanos. E, de outro lado, como resposta ao primeiro grupo, encontramos a crescente criação de aparatos jurídico-internacionais de defesa dos direitos humanos e de repressão jurídico-penal aos crimes contra o direito internacional. Vetores que congregados convergem à desterritorialização "de certas relações sociais e, consequentemente, em uma 'desestatalização' parcial dos poderes que as regulam, em favor de ordenamentos jurídicos não-estatais e de organizações políticas mais amplas”, resultando, muitas vezes, em uma "alegada inadequação (quando não caducidade) da figura do Estado como instância de regulamentação e controlo de certos fenómenos criminais". ${ }^{6}$

4 CAEIRO, Pedro. Fundamento, conteúdo e limites da jurisdição penal do Estado: o caso português. Coimbra: Coimbra Editora, 2010, p. 19-20.

5 Cf., como exemplo de um ataque em escala global de um atentado terrorista no ciberespaço, o caso fictício apresentado por Banks, no qual, a partir de um ataque de DoS, interrompem-se importantes setores da economia, como instituições financeiras e serviços de energia elétrica, desencadeando uma crise em diversos âmbitos, com consequências não só econômicas, mas, também, à integridade física da população (BANKS, William C. An emerging international legal architecture for cyber conflict. In: SANDHOLTZ, Wayne; WHYTOCK, Christopher A. Research handbook on the politics of international law. Cheltenham: Edward Elgar Publishing, 2017, p. 391 e ss.). Apesar de, no exemplo apresentado pelo autor, exagerar-se nas consequências e na forma de perpetração de um possível atentado, pode-se perceber que, a partir do ataque realizado em maio de 2017 contra a rede de hospitais londrinos, a possibilidade de ocorrência da interrupção, por um atentado, de serviços essenciais não é tão fictícia.

6 CAEIRO, Pedro. Fundamento, conteúdo e limites da jurisdição penal do Estado: o caso português. Coimbra: Coimbra Editora, 2010, p. 20-21. 
Vetores cujas consequências influenciam diretamente no âmbito de eficácia do direito penal.

A partir dessa perspectiva, acrescem-se, ainda, os problemas decorrentes das diferenças estabelecidas entre os espaços de atuação do local e do global. Conflitos resultantes de uma atuação de preceitos normativos desenvolvidos a partir de uma perspectiva espacial interna e aplicados às relações estruturadas em uma perspectiva transnacional. Cria-se um problema com as diferenças entre as categorias desenvolvidas a partir de uma específica gnosiologia local e a sua utilização irrefletida em um contexto global.

A partir deste contexto, buscaremos delinear alguns dos problemas decorrentes da constante transnacionalização das condutas - especialmente a partir das novas tecnologias - e suas consequências para o direito. Por meio da revisão bibliográfica sobre o tema, e do amparo de casos selecionados, questionamos: as tradicionais categorias de territorialidade e de delimitação da jurisdição são suficientes para, no contexto internacional, resolver os complexos problemas introduzidos pela Internet?

\section{As novas tecnologias e o seu impacto no diReito penal no contexto global. Breve análise.}

A mudança na realidade sociocultural proporcionada pelas novas tecnologias introduziu espaços de convívio e de interação que substituíram em múltiplos casos a tradicional realidade tangível - como é possível verificar com o ciberespaço - e criou meios, objetos e novas manifestações dos valores então desconhecidos ao indivíduo que, ao longo dos anos, assumiram importante relevo no modo-de-viver do ser humano ${ }^{7}$ e no

7 Cf. SIEBER, Ulrich. Mastering complexity in the global cyberspace: the harmonization of computer-related criminal law. In: LELIEUR, Juliette. Les chemins de l'harmonisation pénale. Paris : Société de Législation Comparée, 2008, p. 132-138 ; NEGROPONTE, Nicholas. A vida digital. Trad. Sérgio Tellaroli. São Paulo: Companhia das Letras, 1995, p. 12, 160-170; GIDDENS, Anthony. Modernity and self-identity: self and society in the late modern age. Califórnia: Stanford University Press, 1991, p. 2 e ss.; CASTELLS, Manuel. A sociedade em rede. Trad. Roneide Venâncio Majer. $5^{\text {a }}$ ed. São Paulo: Paz e Terra, 1999, p. 49; SILVA JÚNIOR, Délio Lins. Crimes 
modo-de-atuar da normatividade jurídico-penal e jurídico-processual. ${ }^{8}$ A ampliação do espaço ocupado pelo ciberespaço é crescente, e, com a importância que essa realidade assume, especialmente no âmbito relacionado à jurisdição, é necessária uma reflexão direcionada às especificidades dessa realidade.

Em virtude das mudanças jurídico-sociais desenvolvidas pelo avanço tecnológico, com a inserção da informática e da Internet e a consequente mudança dos espaços de desenvolvimento pessoais, culturais e sociais, a informática assumiu importante papel na vida do homem. A tecnologia transformou o modo-de-pensar e o modo-de-agir do homem, e, em algumas esferas, pode-se dizer que transformou o próprio mundo do homem.

As novas tecnologias assumiram o protagonismo nas forças geradoras das mudanças socioculturais, de necessário reflexo à normatividade jurídico-penal (na percepção axiológica de proteção da norma) e jurídico-processual (delimitação jurisdicional nos crimes transnacionais). Representadas principalmente pela Internet, as novas tecnologias introduziram novos espaços de atuação da normatividade; espaços não apenas novos, mas que impuseram a necessidade de uma nova forma de pensar os problemas jurídicos e suas consequentes soluções. Em uma complexa sociedade cujo resguardo do direito ocorre a partir de mecanismos cujas bases são estruturadas a partir de conceitos concebidos e desenvolvidos no bojo de um mundo local.

informáticos: sua vitimização e a questão do tipo objetivo. In: D'AVILA, Fabio Roberto; SOUZA, Paulo Vinicius Sporleder de (org.). Direito penal secundário: estudos sobre crimes econômicos, ambientais, informáticos e outras questões. São Paulo: Editora Revista dos Tribunais, 2006, p. 313; ROMEO CASABONA, Carlos María. Dos delitos informáticos ao crime cibernético: uma aproximação conceitual e político-criminal. Doutrinas Essenciais de Direito Penal Econômico e da Empresa, Vol. 6, jul. 2011, p. 509; FONSECA, Antonio. Aspectos econômicos do crime de informática. Revista dos Tribunais, vol. 809, mar. 2003, p. 411; FERREIRA, Lóren Formiga de Pinto; FERREIRA JÚNIOR, José Carlos Macedo de Pinto. Os “crimes de informática” e seu enquadramento no direito penal pátrio. Revista dos Tribunais, vol. 893, mar. 2010, p. 407.

8 Cf., entre outros, CHAN, Janet B. L. The technological game: how information technology is transforming police practice. In: WALL, David S. (org.). Cyberspace crime. Aldershot: Ashgate, 2003, p. 513 e ss. 
Nesse contexto, os crimes de informática representam a principal materialização dessa nova complexidade. São uma forma de criminalidade manifestamente transnacional, especialmente no que concerne aos dados em sistemas informáticas, cujo acesso e armazenamento são facilmente transferidos de forma global (e cujo controle e regulação impõem uma elevada dificuldade e complexidade). Crimes que impõem uma nova e complexa tecnicidade à análise jurídico-penal de suas nuances. Análise que reclama a necessidade de uma especialização técnica, de uma específica expertise alheia ao direito. Representam, ainda, uma variedade de fenômenos, uma transdisciplinaridade, que requerem "um considerável número de instrumentos legais".

A ampliação de uma sociedade global acarretou fundamentais mudanças, não apenas nos aspectos econômico e social, mas, também, político e dogmático-jurídico. ${ }^{10} \mathrm{~A}$ crescente transnacionalização das atividades ${ }^{11}$ passíveis de regulação jurídica acarretou a necessária indagação a importantes questionamentos que, tendo em vista a transterritorialidade e a transestatalidade dessas condutas, levam a serem estabelecidas sob uma perspectiva transfronteiriça. Problemas que necessitam de uma solução pensada também em uma perspectiva global, no "esforço conjunto da comunidade de Estados mundiais". ${ }^{2}$

9 Situação na qual, para Sieber, impõem uma dificuldade ao processo de harmonização: "diferenciando-se, por exemplo, entre a harmonização das várias formas de crime assim como a harmonização entre o direito penal material, o direito processual penal, e o direito internacional de cooperação" (SIEBER, Ulrich. Mastering complexity in the global cyberspace: the harmonization of computer-related criminal law. In: LELIEUR, Juliette. Les chemins de l'harmonisation pénale. Paris : Société de Législation Comparée, 2008, p. 127-8. Trad. Livre)

10 SIEBER, Ulrich. Legal order in a global world: the development of a fragmented system of national, international, and private norms. Max Planck yearbook of United Nations law, vol. 14. Leiden: Martinus Nijhoff Publishers, 2010, p. 4.

11 Cf. SPANG-HANSSEN, Henrik. Cyberspace \& international law on jurisdiction: possibilities of dividing cyberspace into jurisdictions with help of filters and firewall software. Copenhagen: DJOF Publishing, 2004, p. 375.

12 SIEBER, Ulrich. Legal order in a global world: the development of a fragmented system of national, international, and private norms. Max Planck yearbook of United Nations law, vol. 14. Leiden: Martinus Nijhoff Publishers, 2010, p. 5. Trad. Livre. Delmas-Marty, em sentido semelhante, expõe que "a criminalidade transnacional marca uma evolução, dos territórios (extensão geográfica 
Cresce a necessidade de releitura dos critérios de aplicação da lei no espaço e de delimitação jurisdicional, nos quais seja possível, às atividades de caráter transnacional, o seguro estabelecimento de qual norma deverá ser aplicada a cada caso. Na sua falta, por outro lado, abrese espaço à exploração de possíveis lacunas de impunidade. Problemática que se intensifica, ainda, por um viés de aplicabilidade dessas normas, que só podem assim serem efetuadas a partir de uma atuação conjunta das forças nacionais. Deve-se garantir que as "regulações são não apenas nacional, mas também transnacionalmente aplicadas e cumpridas". ${ }^{13}$

Cada vez mais as fronteiras territoriais que delimitam os Estados perdem suas forças. Da mesma forma, o monopólio estatal na criação e coerção da norma, e sua força autoritária, enfraquece-se. Ampliam-se os polos de atuação privada de conglomerados multinacionais e de agentes supranacionais no estabelecimento de parâmetros normativos, assim como sua força no estabelecimento de marcos regulatórios e na transformação dos espaços de abertura à autorregulação. Em igual medida, ampliam-se as forças de influências dos "conglomerados econômicos transnacionais" nas políticas estatais, ${ }^{14}$ não apenas de setores cíveis, mas também criminal - e, especialmente, de política legislativa.

e topografia) para as redes (organização global e topologia) e dos criminosos amadores para os 'empresários do crime”. Assim, pois, "Enquanto o Direito Penal estadual se mantém essencialmente ligado ao território e adaptado aos indivíduos isolados, o crime transnacional, andando a par com a organização em redes transfronteiriças, exige o reforço da cooperação internacional stricto sensu e a adopção de normas comuns, se não totalmente uniformizadas, pelo menos compatíveis entre si” (DELMAS-MARTY, Mireille. O direito penal como ética da mundialização. Revista portuguesa de ciência criminal, Coimbra, ano 14, n. 3, p. 287-304, 2004, p. 290). Cf., também, BORJA JIMÉNEZ, Emiliano. Globalización y concepciones del derecho penal. Estudios penales y criminológicos, Santiago de Compostela, v. XXIX, p. 141-206, 2009, p. 143.

13 SIEBER, Ulrich. Legal order in a global world: the development of a fragmented system of national, international, and private norms. Max Planck yearbook of United Nations law, vol. 14. Leiden: Martinus Nijhoff Publishers, 2010, p. 7. Trad. Livre. Cf., também, SIEBER, Ulrich. Limites do direito penal: princípios e desafios do novo programa de pesquisa em direito penal no instituto Max -Planck de direito penal estrangeiro e internacional. Cadernos Direito GV, v. 5, n. 3, p. 7-88, 2008, p. 9-13.

14 FRANCO, Alberto Silva. Globalização e criminalidade dos poderosos. Revista portuguesa de ciência criminal, Coimbra, ano 10, fasc. 2, p. 183-228, 2000, p. 188. 
O mesmo desenvolvimento tecnológico que permite o crescimento econômico e o estabelecimento de corporações transnacionais e sua atuação relativamente independente dos Estados, também permite a atuação de grupos organizados em perpetrar ilícitos para além das tradicionais limitações do princípio da territorialidade e do direito local. Expõe Delmas-Marty que "até para o mais poderoso Estado no mundo, território não é mais um santuário. Nem a lei nacional é mais apropriada". ${ }^{15} \mathrm{O}$ que leva a autora a dizer: "o aumento dos crimes globais obriga uma nova resposta internacional". ${ }^{16}$

No âmbito jurídico-penal, o problema da aplicação da norma penal não é resolvido apenas pelo princípio da territorialidade, e com força menor ainda, pelo princípio da universalidade.

A aplicação extraterritorial da norma penal esbarra nas imanentes dificuldades impostas pela soberania do Estado, sendo que a única forma legítima de estabelecimento de uma efetiva atuação das forças jurídico-penais em espaços extraterritoriais é a partir da colaboração - e interesse - dos Estados envolvidos; recaindo-se no amparo à cooperação internacional. E a criação de regulações internacionais frequentemente possui um lento desenvolvimento, especialmente pela falta de interesse e de consenso entre os Estados. Motivo pelo qual instituições supranacionais possuem crescente importância na coordenação e desenvolvimento de regras de cooperação, como as recomendações e as resoluções das Nações Unidas, da Organização para a Cooperação e Desenvolvimento Econômico (OCDE), da Organização Mundial do Comércio (OMC), do Banco Mundial, do Conselho da Europa, do Fundo Monetário Internacional (FMI), da Organização Mundial do Trabalho, etc. Apesar de possuírem atuação restrita a determinadas

15 DELMAS-MARTY, Mireille. Global crime calls for global justice. European journal of crime, criminal law and criminal justice, Londres, vol. 10, n. 4., p. 286-293, 2002, p. 286. Trad. Livre. De forma semelhante, também em DELMAS-MARTY, Mireille. O direito penal como ética da mundialização. Revista portuguesa de ciência criminal, Coimbra, ano 14, n. 3, p. 287-304, 2004, p. 288.

16 DELMAS-MARTY, Mireille. Global crime calls for global justice. European journal of crime, criminal law and criminal justice, Londres, vol. 10, n. 4., p. 286-293, 2002, p. 286-7. Trad. Livre. 
áreas, é crescente o desenvolvimento de estruturas governamentais supranacionais no atual contexto global. ${ }^{17}$

Nesse viés, entendemos que o fenômeno global deve ser seguido no sentido de estabelecimento de critérios pertinentes à jurisdição e a marcos regulatórios de aplicação da norma penal; e nos esforços de harmonização legislativa, especialmente em matéria criminal. ${ }^{18}$

Dessa dinâmica, tem-se o problema da legitimidade de um processo legislativo estabelecido a partir de agentes supranacionais. Todavia, a criação de parâmetros para a aplicação da norma penal possui diferentes preceitos que a própria criação da norma penal, distanciando-se, por sua vez, da esfera de legitimidade democrática de estabelecimento do ilícito-típico em lege ferenda. O escopo de legitimidade daquele não é tão restrito quanto deste, porém, sem o segundo, o primeiro torna-se inócuo. I.e., para uma eficaz normativa relacionada à aplicação da lei penal no espaço, requer-se que, em primeiro lugar, haja um esforço global de harmonização da própria norma penal. Em uma atuação em três níveis: harmonização legislativa, legislação relativa à cooperação e instituição de auxílio à cooperação. ${ }^{19}$ As possíveis soluções, por sua vez, esbarram-se nos problemas do ainda presente monopólio de aplicabilidade coercitiva das normas pela força soberana dos Estados e nos preceitos de legitimidade legislativa estabelecidos pelo processo constitucional de lege ferenda.

Desse contexto político-internacional, de um mundo global e de uma ampliação da aparelhagem de prevenção e de segurança, necessitase, pois, de um leitura jurídico-penal, tendo em vista os consequentes reflexos ao modo-de-se-pensar as ciências jurídico-penais. Ciência que, a partir de uma olhar jurídico-penal, é, em sua essência, uma história, um resultado de um momento histórico, que, ao olhar para o passado, trilha

17 SIEBER, Ulrich. Legal order in a global world: the development of a fragmented system of national, international, and private norms. Max Planck yearbook of United Nations law, vol. 14. Leiden: Martinus Nijhoff Publishers, 2010, p. 11, 12 e 14.

Cf. SIEBER, Ulrich. The forces behind the harmonization of criminal law. In: LELIEUR, Juliette (coord.). Les chemins de l'harmonisation pénale. Paris : Société de Législation Comparée, 2008, p. 385- 393.

19 SIEBER, Ulrich. Legal order in a global world: the development of a fragmented system of national, international, and private norms. Max Planck yearbook of United Nations law, vol. 14. Leiden: Martinus Nijhoff Publishers, 2010, p. 35. 
uma perspectiva para uma caminhada já percorrida. Essa manifestação consubstancia-se na tutela de determinados bens, denominados bem jurídico-penais, frutos de um valor transcendente à essa mesma ordem jurídico-penal, verificado por uma orientação axiológico-constitucional; na sua materialização condicionada ao entendimento histórico-comunitário de uma determinada sociedade, cujo objeto será sempre um reflexo da realidade social. ${ }^{20}$

\section{O LIMITE DO TRADICIONAL PRINCÍPIO DA TERRITORIALIDADE NO CONTEXTO DA CRIMINALIDADE GLOBAL.}

Em princípio, tem-se a possibilidade de o Estado aplicar o seu poder jurisdicional sobre todos que no seu espaço territorial se encontram, i.e., "todos os indivíduos que estejam dentro do território do Estado estão

${ }^{20}$ No exato sentido de estudo já desenvolvido por nós em SANTOS, Daniel Leonhardt dos. Ofensividade e bem jurídico-penal: conceitos e fundamentos do modelo de crime como ofensa ao bem jurídico-penal. Revista Brasileira de Ciências Criminais, São Paulo, v. 121, p. 13-50, 2016; SANTOS, Daniel Leonhardt dos. Crimes de informática e bem jurídico-penal: contributo à compreensão da ofensividade em direito penal. Dissertação (Mestrado em Ciências Criminais). PUCRS, Porto Alegre, 2014. Cf., também, D’AVILA, Fabio Roberto. Filosofia e direito penal. Sobre o contributo crítico de um direito penal de base onto-antropológica. In: Ofensividade em direito penal: escritos sobre a teoria do crime como ofensa a bens jurídicos. Porto Alegre: Livraria do Advogado Editora, 2009, p. 53; AZEVEDO, André Moura Lacerda. $\mathrm{O}$ bem jurídico e os crimes de perigo abstrato. In: ; NETO, Orlando Faccini. O bem jurídico-penal: duas visões sobre a legitimidade do direito penal a partir da teoria do bem jurídico. Porto Alegre: Livraria do Advogado, 2013, p. 19; D’AVILA, Fabio Roberto. Aproximações à teoria da exclusiva proteção de bens jurídicos no direito penal contemporâneo. In: ANDRADE, Manuel da Costa, et. al. (org.). Estudos em homenagem ao Prof. Doutor Jorge de Figueiredo Dias, vol. I. Coimbra: Coimbra Ed., 2009; MANTOVANI, Ferrando. Diritto penale: parte generale. $8^{\text {a }}$ Ed. Pádua: CEDAM, 2013, p. 190; STERNBERG-LIEBEN, Detlev. Bien jurídico, proporcionalidad y libertad del legislador penal. In: HEFENDEHL, Roland (org.). La teoría del bien jurídico: ifundamento de legitimación del derecho penal o juego de abalorios dogmático? Madri: Marcial Pons, 2007, p. 111-2; GAEDE, Karsten. Puntos fuertes y puntos flacos de la función legitimadora de la teoría del bien jurídico inmanente al sistema en el ejemplo del fraude de subvenciones. In: HEFENDEHL, Roland (org.). La teoría del bien jurídico: ¿ fundamento de legitimación del derecho penal o juego de abalorios dogmático? Madri: Marcial Pons, 2007, p. 269. 
subjugados ao seu poder coercitivo". ${ }^{21}$ Relação tradicionalmente concebida em virtude de, ao exercício desse poder jurisdicional do Estado, estar associado a relação de manifestação do poder soberano desse mesmo Estado, limitado por preceitos estabelecidos para além da sua esfera de discricionariedade interna, mas delimitado por preceitos estabelecidos pela normatividade jurídico-internacional. Ocorre que, da expansão da criminalidade para além do restrito espaço local do Estado, especialmente com a manifestação de um mundo global e da expansão da criminalidade transnacional, tem-se exigido dos Estados novos meios para a repressão desses crimes, necessitando, em certa medida, o alargamento dos critérios de delimitação da lei penal no espaço, ${ }^{22}$ encontrando-se na denominada extraterritorialidade a consubstanciação desses elementos.

A ampliação da necessidade de atuação extraterritorial à crescente criminalidade transnacional, estabelece-se, paralelamente, o incremento da necessidade de uma atuação dos poderes associados à jurisdição prerrogativa também na esfera global: no fortalecimento dos aparatos de colaboração internacional e dos auxílios mútuos das agências e órgãos governamentais. Intensificação que, para Bronitt, possui dois efeitos: um positivo, representado pela troca de conhecimento e desenvolvimento prático das agências e o desenvolvimento de uma polícia globalizada profissional; outro negativo, representado pelo aumento de eventuais espaços de discricionariedade policial, de operacionalidade estabelecida fora dos espaços de controle governamental. ${ }^{23}$ Riscos de aumento de uma prática estabelecida fora do amparo da normatividade jurídico-penal e jurídico-processual. O aumento das práticas de cooperação jurídica internacional informal representa, em certa medida, o reflexo desse panorama.

21 KELSEN, Hans. Principles of international law. $2^{\mathrm{a}}$ ed. Nova York: Holt, Rinehart and Winston Inc., 1966, p. 344. Trad. Livre.

LEITE, Inês Ferreira. O conflito de leis penais: natureza e função do direito penal internacional. Coimbra: Coimbra Editora, 2008, p. 19.

23 BRONITT, Simon. Conclusion: shifting paradigms: jurisdiction and criminal justice cooperation in the shadow of law. In: HUFNAGEL, Saskia, et. al. (org.). Cross-border law enforcement: regional law enforcement cooperation: European, Australian and Asia-Pacific perspectives. London: Routledge, 2012, p. 281. 
A partir da delimitação jurídico-internacional, especialmente com a decisão do caso Lotus ${ }^{24}$, entende-se que o principal limite à atuação do poder jurisdicional dos Estados encontra-se na sua jurisdição prerrogativa. I.e., no limite de atuação das forças de realização dos mandamentos propugnados a partir das jurisdições prescritiva e judicativa. ${ }^{25}$ Aos Estados, assim, cabe uma ampla discricionariedade de estabelecimento dos limites internos da sua própria territorialidade e extraterritorialidade, esbarrando-se na delimitação do fazer cumprir a essa delimitação o próprio limite estabelecido pelo espaço dos Estados

24 O caso Lotus, julgado pela Corte Permanente de Justiça Internacional em 7 de setembro de 1927, representa uma das decisões mais importantes para o estudo da matéria relacionada à jurisdição penal no âmbito internacional, tendo em vista ter sido o primeiro acórdão no qual se aborda, em sede de tribunal internacional, sobre a competência dos Estados para a determinação da aplicação da sua lei penal; e, ainda, em virtude da diversidade de opiniões apresentadas pelos votos. Cf. SANTOS, Daniel Leonhardt dos. O conflito de jurisdição nos crimes de informática transnacionais. Tese (Doutorado em Ciências Criminais). PUCRS, Porto Alegre, 2018.

25 Diferenciação importante. Jurisdição prescritiva representa o poder que possui um Estado de decidir quais condutas sobre as quais recai o direito e o seu âmbito de aplicabilidade. Jurisdição judicativa representa o poder de decidir sobre as condutas a partir da aplicação das normas pelos órgãos jurisdicionais. Por sua vez, jurisdição prerrogativa representa o efetivo cumprimento da decisão legal ao caso concreto. Cf. CAEIRO, Pedro. Fundamento, conteúdo e limites da jurisdição penal do Estado: o caso português. Coimbra: Coimbra Editora, 2010, p. 42 e ss.; CAEIRO, Pedro. Jurisdiction in criminal matters in the EU: negative and positive conflicts, and beyond. Kritv. München, A. 93, n. 4, p. 366-379, 2010, p. 368-9; CAEIRO, Pedro. A jurisdição penal da União Europeia como meta-jurisdição: em especial, a competência para legislar sobre as bases de jurisdição nacionais. In: CORREIA, Fernando Alves, et. al. Estudos em homenagem ao Prof. Doutor José Joaquim Gomes Canotilho. Vol. III. Direitos e interconstitucionalidades: entre dignidade e cosmopolismo. Coimbra: Coimbra Editora, 2012, p. 181-2; SHAW, Malcolm N. International law. 6a Ed. Cambridge: Cambridge University Press, 2008, p. 649; O'KEEFE, Roger. International criminal law. Oxford: Oxford University Press, 2015, p. 4; RYNGAERT, Cedric. Jurisdiction in international law. $2^{\mathrm{a}}$ ed. Oxford: University Press, 2015, p. 9; KOHL, Uta. Jurisdiction in cyberspace. In: TSAGOURIAS, Nicholas; BUCHAN, Russell. Research handbook on International law and cyberspace. Cheltenham: Edward Elgar Publishing, 2015, p. 34; MANN, F. A. Studies in international law. Oxford: Clarendon Press, 1973, p. 6; AUGUST, Ray. International cyber-jurisdiction: a comparative analysis. In: CARR, Indira (org.). Computer crime. Farnham: Ashgate, 2009, p. 449. 
outros. ${ }^{26}$ Limite estabelecido - para além da própria ideia de Estados soberanos -, nos princípios fundamentais da ordem internacional representado especialmente pelo princípio de não intervenção -, na necessidade de conexão e na existência expressa de proibição de atuação.

O princípio da territorialidade corresponde à própria ideia associada à territorialidade estatal. Como resultado da manifestação soberana de um Estado, considera-se legítima a legislação do país dentro do qual, em seu território, foi praticado determinado crime. Delimitação que independe da nacionalidade do agente do fato delitivo, do titular do bem jurídico-penal ou do interesse lesionado, pois, a partir do entendimento de independência nacional (soberania), cada Estado possui a legitimidade de aplicação da sua normatividade jurídico-penal interna aos ilícito-típicos praticados dentro do seu espaço territorial. Entende-se, tradicionalmente, que a pena deve ser atribuída ao espaço dentro do qual ocorreu a prática do fato danoso, como também em virtude de uma maior facilidade de investigação - em um interesse de uma efetiva e célere persecução - por maior facilidade de acesso aos elementos probatórios. ${ }^{27}$

Sua atuação estabelece-se a partir da razão segundo a qual a incidência do poder punitivo do Estado deve-se limitar ao seu próprio espaço territorial soberano, e consequente não incidência sobre o espaço territorial soberano doutro Estado pelos mesmos motivos que o legitima a atuar sobre o seu próprio. ${ }^{28} \mathrm{Tem}-\mathrm{se}$, assim, associado ao princípio da territorialidade, um duplo sentido: a delimitação do âmbito de aplicação

${ }^{26}$ HIRST, Michael. Jurisdiction and the ambit of the criminal law. Oxford: University Press, 2003, p. 44.

27 Cf. HUNGRIA, Nélson. Comentários ao código penal, volume I, tomo I: arts. $1^{\mathrm{o}}$ ao $10.5^{\mathrm{a}}$ ed. Rio de Janeiro: Forense, 1976, p. 154 e ss.; LISZT, Franz von. Tratado de direito penal allemão, volume I. Ed. fac-sim. Brasília: Senado Federal, Conselho Editorial, 2006, p. 156 e ss.; FRAGOSO, Heleno Cláudio. Lições de Direito Penal. $16^{\mathrm{a}}$ ed. Rio de Janeiro: Forense, 1991, p. 132 e ss.; JIMÉNEZ DE ASÚA, Luis. Tratado de derecho penal, tomo II: filosofia y ley penal. $3^{\mathrm{a}}$ ed. Buenos Aires: Editorial Losada, 1964, p. 751 e ss.; COSTA JUNIOR, Paulo José da. Código Penal Comentado. $8^{\mathrm{a}}$ ed. São Paulo: DPJ Editora, 2005, p. 14 e ss.; CARLOS PEREZ, Luis. Tratado de derecho penal: tomo I. Bogotá: Editorial Temis, 1967, p. 365 e ss. 
da lei penal no espaço; e, em conjunto, a delimitação da "competência internacional atribuída aos órgãos jurisdicionais nacionais". ${ }^{29}$

A atuação do princípio da territorialidade, todavia, não é absoluta. Admitem-se rupturas, ${ }^{30}$ que serão estabelecidas por princípios outros de aplicação da lei penal no espaço - formadores de um conjunto -, a partir dos princípios da defesa, da universalidade e da personalidade. Pela brevidade deste trabalho, todavia, não iremos desenvolver cada um deles. ${ }^{31}$

\section{O LIMITE DA JURISDIÇÃO PRERROGATIVA NO ÂMBITO ONLINE}

O problema imposto à jurisdição prerrogativa, no âmbito online transnacional, circunscreve-se ao limite de atuação do poder jurisdicional do Estado. Limite estabelecido, em uma perspectiva internacional, pelo princípio de não intervenção, restringindo-o ao espaço territorial do próprio Estado.

A jurisdição prerrogativa é, pois, estritamente territorial..$^{32} \mathrm{E}$ assim foi estabelecido pelo caso Lotus: "a primeiro e principal restrição imposta pelo direito internacional a um Estado é que (...) não pode ele exercer o seu poder sob nenhuma forma no território de outro Estado". ${ }^{33}$ Todavia, no âmbito online, como exercer um controle no contexto estabelecido por essa limitação? A resposta ao problema estabelece-se, na prática, a partir dos instrumentos legítimos de atuação local sobre as condutas que possuem um efeito global. I.e., a partir das ferramentas disponíveis dentro do próprio território do Estado contra àquilo que se quer controlar no

29 LEITE, Inês Ferreira. O conflito de leis penais: natureza e função do direito penal internacional. Coimbra: Coimbra Editora, 2008, p. 24.

30 AMBOS, Kai. Los fundamentos del ius puniendi nacional, en particular su aplicación extraterritorial. Persona y Derecho, n. 51, p. 225-254, 2004, p. 233.

31 Cf. SANTOS, Daniel Leonhardt dos. O conflito de jurisdição nos crimes de informática transnacionais. Tese (Doutorado em Ciências Criminais). PUCRS, Porto Alegre, 2018.

32 KOHL, Uta. Jurisdiction in cyberspace. In: TSAGOURIAS, Nicholas; BUCHAN, Russell. Research handbook on International law and cyberspace. Cheltenham: Edward Elgar Publishing, 2015, p. 51.

33 PERMANENT COURT OF INTERNATIONAL JUSTICE. The Case of the S.S. Lotus (Fr. v. Turk.). 7 de set. de 1927. Trad. Livre. 
próprio território, acarretando, consequentemente, uma fragmentação ${ }^{34}$ do global espaço do ciberespaço. Assim, pois, com os instrumentos locais, como o bloqueio de determinado site; a solicitação às empresas de cartão de crédito de impedimento de compra em determinado site; a exigência de cooperação das subsidiárias de grandes corporações; estabelece-se uma espécie de "tampão" ao problema do limite territorial imposto à jurisdição prerrogativa.

Nesse contexto, tem-se, p.e., o caso Twentieth Century Fox Film Corp \& Ors v. British Telecommunications Plc (2011), no qual foi exigido o bloqueio, em território britânico, de um site que fornecia para download conteúdo pirata; ${ }^{35}$ e o caso ocorrido, na Alemanha, de bloqueio, a pedido das autoridades policiais, pelo Twitter de contas neonazistas em $2014 .^{36}$

Em tal perspectiva, com a fragmentação da territorialidade no ciberespaço e com a tentativa de os Estados exercerem o seu poder jurisdicional sobre esse espaço, cria-se um sensível problema: o respeito às garantias fundamentais do homem, dentre elas o acesso à informação, a liberdade de expressão e a inviolabilidade da intimidade. Uma excessiva e autoritária atuação das forças Estatais sobre determinadas condutas praticadas na Internet pode levar à redução - ou mesmo à inibição - do avanço tecnológico no ciberespaço, tendo em vista a exploração, a descoberta e a curiosidade associadas à criação de softwares destinados aos mais diversos usos.

34 Conforme expõe Kohl, “a aplicação cega do direito nacional à Internet transnacional não pode deixar de levar à sua fragmentação territorial em ciberespaços nacionais, com custos inerentes à liberdade de expressão, bem como ao intercâmbio econômico, político, social e cultural. Possivelmente, a Internet transnacional esteja sofrendo a tragédia dos comuns ou a morte por mil cortes: cada vez que um Estado reivindica seu direito de aplicar sua versão regulatória peculiar da 'boa vida' ao mundo on-line e cada vez que essa afirmação é aplicada via conformidade voluntária ou bloqueio de fronteira, a transnacionalidade é levemente impedida" (KOHL, Uta. Jurisdiction in cyberspace. In: TSAGOURIAS, Nicholas; BUCHAN, Russell. Research handbook on International law and cyberspace. Cheltenham: Edward Elgar Publishing, 2015, p. 54. Trad. Livre).

Cf. KOHL, Uta. Jurisdiction in cyberspace. In: TSAGOURIAS, Nicholas; BUCHAN, Russell. Research handbook on International law and cyberspace. Cheltenham: Edward Elgar Publishing, 2015, p. 52.

36 Cf. CONNOLLY, Kate. Twitter blocks neo-Nazi account in Germany. The Guardian, de 18 de out. de 2012. 
Por mais que o exercício da jurisdição prerrogativa tenha no território o seu limite, tal circunstância não representa uma barreira intransponível para o exercício de um certo controle da normatividade jurídico-penal sobre o ciberespaço, especialmente pelos instrumentos de cooperação internacional existentes.

Um exemplo da possibilidade de atuação global corresponde à Operação Buccaneer, na qual 70 mandados de busca e apreensão foram executados simultaneamente nos Estados Unidos, no Reino Unido, na Austrália, na Noruega, na Suíça e na Finlândia, em 2001, com o intuito de desmantelar um grupo organizado de pirataria de softwares que atuava de forma global no âmbito online. ${ }^{37}$ Todavia, tais operações não apenas exigem o estabelecimento de uma cooperação internacional, mas uma coordenada e sofisticada atuação dos órgãos de investigação. Atuação que, para Urbas, mostra-se "cada vez mais eficaz". ${ }^{38}$ Por outro lado, a eficácia de operações globais - como a realizada pela Operação Buccaneer -, restringe-se pelas dificuldades formais e materiais associadas a uma investigação internacional; atuação que, em virtude do necessário e imprescindível respeito às garantias fundamentais, possui uma velocidade inevitavelmente diferente daqueles que praticam a conduta. Diferença que tende a acentuar-se com a crescente globalidade da atuação criminal no ciberespaço.

Há, ainda, a possibilidade de cumprimento voluntário dos preceitos estabelecidos por uma decisão de um Estado outro que não o de origem de uma determina companhia. Como, p.e., no caso LICRA \& UEJF v. Yahoo! Inc. \& Yahoo France, no qual, a partir da decisão proferida pelo tribunal francês, Yahoo! voluntariamente, a partir da sua sede nos Estados Unidos, cumpriu a imposição estabelecida pela decisão da corte. ${ }^{39}$

37 Cf. as informações oficiais do Departamento de Justiça dos Estados Unidos, disponíveis em: https://web.archive.org/web/20111230045615/http://www. cybercrime.gov/ob/OBMain.htm\#pr, (acessado em: 19 de maio de 2019).

38 URBAS, Gregor. Cross-national investigation and prosecution of intellectual property crimes: the example of "Operation Buccaneer". Crime, law and social change, v. 46, n. 4-5, p. 207-221, Springer, 2006, p. 221. Trad. Livre.

39 Trata-se de um caso no qual duas organizações francesas de origem judaica realizaram uma ação contra Yahoo! Inc. (uma corporação estadunidense) e sua subsidiária francesa pela venda em sites terceirizados da companhia de objetos nazistas, em desacordo com o art. R645-1 do código penal francês. 
Em certa medida, o cumprimento voluntário, em tais circunstância, não é incomum no âmbito cível em virtude da intenção na atuação dos negócios empresariais naquele determinado território, e por uma questão especialmente associada à imagem da empresa, que buscará manter-se distante da negatividade proporcionada por um processo criminal e eventual negação do cumprimento das exigências legais. Motivo pelo qual, quando uma corporação busca a inserção dos seus negócios em um Estado estrangeiro, mantém-se filiais com funcionários especializados para o cumprimento dos preceitos jurídicos locais - além de outras funções -, ou mesmo sites direcionados especificamente ao público (e às demandas legais) daquele território. ${ }^{40}$

Todavia, para além do cumprimento voluntário, a atuação do exercício da jurisdição prerrogativa, quando da negação de cumprimento do mandamento da sentença, encontra, nos limites territoriais do Estado, uma barreira de difícil transposição. E, quando analisado sob o prisma de uma sentença condenatória criminal, tal limite mostra-se ainda mais saliente.

\section{Considerações finais}

Buscamos, a partir das reflexões expostas neste artigo, responder à seguinte pergunta: as tradicionais categorias de territorialidade e de delimitação da jurisdição são suficientes para, no contexto internacional, resolver os complexos problemas introduzidos pela Internet?

No contexto apresentado, concluímos:

Foi decidido pelo tribunal francês a favor dos autores, contra a Yahoo! e sua subsidiária, pois o dano foi sofrido dentro do território francês tendo em vista a sua acessibilidade nesse território. Para a decisão, não importou que o site em questão era mantido nos Estados Unidos, nem no fato de a empresa possuir um específico domínio de acesso francês (.fr), da mesma forma de a conduta de venda de objetos nazistas ser lícita no país de origem: em virtude de sua possibilidade de acesso na França, foi considerado que Yahoo! Inc. deve obedecer às regras daquele território. Cf. SANTOS, Daniel Leonhardt dos. O conflito de jurisdição nos crimes de informática transnacionais. Tese (Doutorado em Ciências Criminais). PUCRS, Porto Alegre, 2018.

40 KOHL, Uta. Jurisdiction and the internet: a study of regulatory competence over online activity. Cambridge: Cambridge University Press, 2007, p. 206 e ss. 
As tradicionais teorias de aplicação lei penal no espaço representam uma construção teórica desenvolvida em um tempo no qual ao espaço e à normatividade jurídico-penal recaía um modo-de-pensar a aplicação do direito penal a partir de uma perspectiva local, dissonante dos complexos problemas hoje estabelecidos pelo mundo global, especialmente acentuados pela ascensão das novas tecnologias e do ciberespaço.

Por um viés teórico, essa dissonância mostra-se acentuada em virtude da tentativa de limitação espaço-territorial daquilo que hoje se manifesta de forma global, de limitação de exercício do poder jurisdicional aos estreitos espaços do próprio Estado, esquecendo-se da sua inserção na dinâmica global. Em semelhante medida, o mais importante princípio reitor da matéria, a territorialidade, mostra-se em crise. O que possibilita a ampliação da importância dos outros princípios que, por si só, mostramse também insuficientes para abarcar, de forma heurística, a matéria.

Todavia, a principal insuficiência, em âmbito global, das tradicionais teorias da lei penal no espaço encontra-se no seu viés prático, na realidade em concreto da sua aplicação. E isso ocorre, em virtude da dinâmica estabelecida pela política-internacional, da relação horizontal de Estado soberanos e do exercício da jurisdição prerrogativa transestatal. Elementos de complexidade que não estão presentes na normatividade jurídico-penal local, mas que, ao projetar a análise do espaço ao âmbito jurídico-internacional, sobressaem-se. Ao direito internacional, não há respostas teóricas unânimes, nem harmonia de resultados quando falamos no âmbito de atuação do ius puniendi estatal. Se nem à própria matéria da normatividade jurídico-penal-internacional há unanimidade de conceitos e premissas, muito menos à sua precisa delimitação ao caso concreto.

Problemática que se intensifica quando refletimos o problema a partir dos crimes de informática transnacionais. Nesse âmbito, a pergunta pela delimitação da jurisdição, p.e., pode ser resumida à seguinte inquirição: em que circunstâncias um Estado pode aplicar a sua lei penal? A título de exemplo: os serviços de aposta online proporcionados por servidores localizados na Antígua precisam obedecer às regras estabelecidos pelos Estados Unidos sobre apostas? Um site chinês de notícias que possui o domínio cnnews.com, ao invés de .cn, precisa respeitar as regras estadunidenses de marca registrada? A plataforma de busca do Google precisa respeitar as regras europeia de proteção de dados? O site de vendas do 
Yahoo! estadunidense precisa respeitar com as leis francesas e alemãs sobre objetos nazistas? Pode um site holandês vender remédios na Alemanha sem lá estar registrado? Um site de pornografia estadunidense deve respeitar as regras britânicas de obscenidade?

Tais exemplos, baseados em casos reais, ${ }^{41}$ possuem, ainda, a complexidade de, no local onde está hospedado cada um desses serviços online, não serem consideradas, as condutas, crimes. E, em alguns, como no caso do site de venda de remédios holandês, estar legitimado por cumprir todos os requisitos legais do território que se encontra, porém, no local onde foram acessados, serem ilícitos os serviços.

A complexidade do problema da delimitação jurisdicional das atividades praticadas no ciberespaço recai, em um primeiro olhar, na dificuldade de delimitação territorial das condutas que nesse espaço são praticadas, tendo em vista estabelecerem-se em um espaço desassociado do mundo físico onde normalmente os tradicionais crimes são praticados. Imaterialidade que possibilita uma expansão territorial de difícil delimitação, especialmente pela ausência de consenso nas suas fronteiras. Ou mesmo na sua própria existência. Imaterialidade, todavia, que não é absoluta, pois o ciberespaço (e as condutas nele praticadas) não possui a sua manifestação em um total espaço vazio. Ao contrário, para a sua existência, faz-se necessária a também existência de uma ligação com o espaço material de convívio do homem, seja no espaço física dos servidores, dos sistemas informáticos ou mesmo da conduta físico-mecânica de um indivíduo que acessa tal sistema. E é a partir dessas ligações que os Estados buscam, inicialmente, as soluções dos problemas territoriais estabelecidos no mundo online. ${ }^{42} \mathrm{E}$ assim ocorre, pois, para o legítimo exercício do poder jurisdicional de um Estado, faz-se necessária a presença de uma conexão do ilícito-típico com o Estado, seja pela territorialidade, seja pelos interesses de proteção nacionais. Presencia-se, dessa forma,

${ }^{41}$ Cf. KOHL, Uta. Jurisdiction in cyberspace. In: TSAGOURIAS, Nicholas; BUCHAN, Russell. Research handbook on International law and cyberspace. Cheltenham: Edward Elgar Publishing, 2015, p. 35 e ss.

${ }^{42}$ Sobre as soluções adotadas pelos Estados, Cf. SANTOS, Daniel Leonhardt dos. O conflito de jurisdição nos crimes de informática transnacionais. Tese (Doutorado em Ciências Criminais). PUCRS, Porto Alegre, 2018. 
no espaço online, uma extensão dessas formas de conexão/ligação do fato criminoso com o Estado.

Por fim, a partir da delimitação jurídico-internacional, o principal limite à atuação do poder jurisdicional dos Estados encontra-se, hoje, na sua jurisdição prerrogativa. Os Estados possuem uma ampla discricionariedade de estabelecimento dos limites internos da sua própria territorialidade e extraterritorialidade. Esbarram-se, todavia, na delimitação do fazer cumprir a essa delimitação o próprio limite estabelecido pelo espaço soberano dos outros Estados. Situação complexa na qual a decisão normativa encontra-se subjugada aos interesses soberanos dos Estados.

\section{REFERÊNCIAS}

AMBOS, Kai. Los fundamentos del ius puniendi nacional, en particular su aplicación extraterritorial. Persona y Derecho, n. 51, p. 225-254, 2004.

AZEVEDO, André Moura Lacerda. O bem jurídico e os crimes de perigo abstrato. In: AZEVEDO, André Moura Lacerda; NETO, Orlando Faccini. O bem jurídico-penal: duas visões sobre a legitimidade do direito penal a partir da teoria do bem jurídico. Porto Alegre: Livraria do Advogado, 2013.

AUGUST, Ray. International cyber-jurisdiction: a comparative analysis. In: CARR, Indira (org.). Computer crime. Farnham: Ashgate, 2009.

BACIGALUPO, Enrique. Principios de derecho penal: parte general. $3^{\text {a }}$ ed. Madri: Ediciones Akal, 1994.

BANKS, William C. An emerging international legal architecture for cyber conflict. In: SANDHOLTZ, Wayne; WHYTOCK, Christopher A. Research handbook on the politics of international law. Cheltenham: Edward Elgar Publishing, 2017.

BORJA JIMÉNEZ, Emiliano. Globalización y concepciones del derecho penal. Estudios penales y criminológicos, Santiago de Compostela, v. XXIX, p. 141-206, 2009.

BRONITT, Simon. Conclusion: shifting paradigms: jurisdiction and criminal justice cooperation in the shadow of law. In: HUFNAGEL, Saskia, et. al. (org.). Cross-border law enforcement: regional law enforcement cooperation: European, Australian and Asia-Pacific perspectives. London: Routledge, 2012.

CAEIRO, Pedro. A jurisdição penal da União Europeia como meta-jurisdição: em especial, a competência para legislar sobre as bases de jurisdição nacionais. 
In: CORREIA, Fernando Alves, et. al. Estudos em homenagem ao Prof. Doutor José Joaquim Gomes Canotilho. Vol. III. Direitos e interconstitucionalidades: entre dignidade e cosmopolismo. Coimbra: Coimbra Editora, 2012.

CAEIRO, Pedro. Fundamento, conteúdo e limites da jurisdição penal do Estado: o caso português. Coimbra: Coimbra Editora, 2010.

CAEIRO, Pedro. Jurisdiction in criminal matters in the EU: negative and positive conflicts, and beyond. Kritv. München, A. 93, n. 4, p. 366-379, 2010.

CARLOS PEREZ, Luis. Tratado de derecho penal: tomo I. Bogotá: Editorial Temis, 1967.

CASTELLS, Manuel. A sociedade em rede. Trad. Roneide Venâncio Majer. $5^{\mathrm{a}}$ ed. São Paulo: Paz e Terra, 1999.

CHAN, Janet B. L. The technological game: how information technology is transforming police practice. In: WALL, David S. (org.). Cyberspace crime. Aldershot: Ashgate, 2003.

CONNOLLY, Kate. Twitter blocks neo-Nazi account in Germany. The Guardian, de 18 de out. de 2012.

COSTA JUNIOR, Paulo José da. Código Penal Comentado. $8^{\mathrm{a}}$ ed. São Paulo: DPJ Editora, 2005.

D’AVILA, Fabio Roberto. Aproximações à teoria da exclusiva proteção de bens jurídicos no direito penal contemporâneo. In: ANDRADE, Manuel da Costa, et. al. (org.). Estudos em homenagem ao Prof. Doutor Jorge de Figueiredo Dias, vol. I. Coimbra: Coimbra Ed., 2009.

D’AVILA, Fabio Roberto. Filosofia e direito penal. Sobre o contributo crítico de um direito penal de base onto-antropológica. In: Ofensividade em direito penal: escritos sobre a teoria do crime como ofensa a bens jurídicos. Porto Alegre: Livraria do Advogado Editora, 2009.

DELMAS-MARTY, Mireille. Global crime calls for global justice. European journal of crime, criminal law and criminal justice, Londres, vol. 10, n. 4., p. 286-293, 2002. DELMAS-MARTY, Mireille. O direito penal como ética da mundialização. Revista portuguesa de ciência criminal, Coimbra, ano 14, n. 3, p. 287-304, 2004.

FARIA COSTA, José de. Direito penal e globalização: reflexões não locais e pouco globais. Coimbra: Coimbra Editora, 2010.

FARIA COSTA, José de. O mundo de hoje e o direito penal: primeira aproximação. In: D’AVILA, Fabio Roberto; SANTOS, Daniel Leonhardt dos. Direito penal e política criminal. Porto Alegre: EDIPUCRS, 2016. 
FARIA COSTA, José de. O princípio da territorialidade: entre Portugal e o Brasil. Revista de legislação e de jurisprudência, Coimbra, n. 3950, p. 285-293, 2008.

FERREIRA, Lóren Formiga de Pinto; FERREIRA JÚNIOR, José Carlos Macedo de Pinto. Os "crimes de informática" e seu enquadramento no direito penal pátrio. Revista dos Tribunais, vol. 893, mar. 2010.

FONSECA, Antonio. Aspectos econômicos do crime de informática. Revista dos Tribunais, vol. 809, mar. 2003.

FRAGOSO, Heleno Cláudio. Lições de Direito Penal. 16 ${ }^{\mathrm{a}}$ ed. Rio de Janeiro: Forense, 1991.

FRANCO, Alberto Silva. Globalização e criminalidade dos poderosos. Revista portuguesa de ciência criminal, Coimbra, ano 10, fasc. 2, p. 183-228, 2000.

GAEDE, Karsten. Puntos fuertes y puntos flacos de la función legitimadora de la teoría del bien jurídico inmanente al sistema en el ejemplo del fraude de subvenciones. In: HEFENDEHL, Roland (org.). La teoría del bien jurídico: ¿fundamento de legitimación del derecho penal o juego de abalorios dogmático? Madri: Marcial Pons, 2007.

GIDDENS, Anthony. Modernity and self-identity: self and society in the late modern age. Califórnia: Stanford University Press, 1991.

HIRST, Michael. Jurisdiction and the ambit of the criminal law. Oxford: University Press, 2003.

HUNGRIA, Nélson. Comentários ao código penal, volume I, tomo I: arts. $1^{\circ}$ ao 10. $5^{\mathrm{a}}$ ed. Rio de Janeiro: Forense, 1976.

JIMÉNEZ DE ASÚA, Luis. Tratado de derecho penal, tomo II: filosofia y ley penal. $3^{\mathrm{a}}$ ed. Buenos Aires: Editorial Losada, 1964.

KELSEN, Hans. Principles of international law. $2^{\text {a }}$ ed. Nova York: Holt, Rinehart and Winston Inc., 1966.

KOHL, Uta. Jurisdiction and the internet: a study of regulatory competence over online activity. Cambridge: Cambridge University Press, 2007.

KOHL, Uta. Jurisdiction in cyberspace. In: TSAGOURIAS, Nicholas; BUCHAN, Russell. Research handbook on International law and cyberspace. Cheltenham: Edward Elgar Publishing, 2015.

LEITE, Inês Ferreira. O conflito de leis penais: natureza e função do direito penal internacional. Coimbra: Coimbra Editora, 2008.

LISZT, Franz von. Tratado de direito penal allemão, volume I. Ed. fac-sim. Brasília: Senado Federal, Conselho Editorial, 2006. 
MANN, F. A. Studies in international law. Oxford: Clarendon Press, 1973.

MANTOVANI, Ferrando. Diritto penale: parte generale. $8^{\text {a }}$ Ed. Pádua: CEDAM, 2013. NEGROPONTE, Nicholas. A vida digital. Trad. Sérgio Tellaroli. São Paulo: Companhia das Letras, 1995.

O’KEEFE, Roger. International criminal law. Oxford: Oxford University Press, 2015. ROMEO CASABONA, Carlos María. Dos delitos informáticos ao crime cibernético: uma aproximação conceitual e político-criminal. Doutrinas Essenciais de Direito Penal Econômico e da Empresa, Vol. 6, jul. 2011.

RYNGAERT, Cedric. Jurisdiction in international law. $2^{\text {a }}$ ed. Oxford: University Press, 2015.

SANTOS, Daniel Leonhardt dos. Crimes de informática e bem jurídico-penal: contributo à compreensão da ofensividade em direito penal. Dissertação (Mestrado em Ciências Criminais). PUCRS, Porto Alegre, 2014.

SANTOS, Daniel Leonhardt dos. O conflito de jurisdição nos crimes de informática transnacionais. Tese (Doutorado em Ciências Criminais). PUCRS, Porto Alegre, 2018.

SANTOS, Daniel Leonhardt dos. Ofensividade e bem jurídico-penal: conceitos e fundamentos do modelo de crime como ofensa ao bem jurídico-penal. Revista Brasileira de Ciências Criminais, São Paulo, v. 121, p. 13-50, 2016.

SHAW, Malcolm N. International law. 6a Ed. Cambridge: Cambridge University Press, 2008.

SIEBER, Ulrich. Legal order in a global world: the development of a fragmented system of national, international, and private norms. Max Planck yearbook of United Nations law, vol. 14. Leiden: Martinus Nijhoff Publishers, 2010.

SIEBER, Ulrich. Limites do direito penal: princípios e desafios do novo programa de pesquisa em direito penal no instituto Max-Planck de direito penal estrangeiro e internacional. Cadernos Direito GV, v. 5, n. 3, p. 7-88, 2008.

SIEBER, Ulrich. Mastering complexity in the global cyberspace: the harmonization of computer-related criminal law. In: LELIEUR, Juliette. Les chemins de l'harmonisation pénale. Paris : Société de Législation Comparée, 2008.

SIEBER, Ulrich. The forces behind the harmonization of criminal law. In: LELIEUR, Juliette (coord.). Les chemins de l'harmonisation pénale. Paris : Société de Législation Comparée, 2008.

SILVA JÚNIOR, Délio Lins. Crimes informáticos: sua vitimização e a questão do tipo objetivo. In: D’AVILA, Fabio Roberto; SOUZA, Paulo Vinicius Sporleder de 
(org.). Direito penal secundário: estudos sobre crimes econômicos, ambientais, informáticos e outras questões. São Paulo: Editora Revista dos Tribunais, 2006.

SPANG-HANSSEN, Henrik. Cyberspace \& international law on jurisdiction: possibilities of dividing cyberspace into jurisdictions with help of filters and firewall software. Copenhagen: DJOF Publishing, 2004.

STERNBERG-LIEBEN, Detlev. Bien jurídico, proporcionalidad y libertad del legislador penal. In: HEFENDEHL, Roland (org.). La teoría del bien jurídico: ¿fundamento de legitimación del derecho penal o juego de abalorios dogmático? Madri: Marcial Pons, 2007.

URBAS, Gregor. Cross-national investigation and prosecution of intellectual property crimes: the example of "Operation Buccaneer". Crime, law and social change, v. 46, n. 4-5, p. 207-221, 2006.

\section{Informações adicionais e declarações dos autores (integridade científica)}

Agradecimentos (acknowledgement): a CAPES, pelo financiamento dos estudos acadêmicos; e aos avaliadores, que contribuíram para o desenvolvimento deste trabalho com as críticas traçadas no blind-review.

Declaração de conflito de interesses (conflict of interest declaration): o autor confirma que não há conflitos de interesse na realização das pesquisas expostas e na redação deste artigo.

Declaração de autoria e especificação das contribuições (declaration of authorship): todas e somente as pessoas que atendem os requisitos de autoria deste artigo estão listadas como autores; todos os coautores se responsabilizam integralmente por este trabalho em sua totalidade.

Declaração de ineditismo e originalidade (declaration of originality): o autor assegura que o texto aqui publicado não foi divulgado anteriormente em outro meio e que futura republicação somente se realizará com a indicação expressa da referência desta publicação original; também atesta que não há plágio de terceiros ou autoplágio. 


\section{Dados do processo editorial}

(http://www.ibraspp.com.br/revista/index.php/RBDPP/about/editorialPolicies)

- Recebido em: 30/03/2019

- Controle preliminar e verificação de plágio: 09/04/2019

- Avaliação 1: 20/04/2019

- Avaliação 2: 24/04/2019

- Avaliação 3: 01/05/2019

- Decisão editorial preliminar: 12/05/2019

- Retorno rodada de correções: 21/05/2019

- Decisão editorial final: 23/05/2019

\section{COMO CITAR ESTE ARTIGO:}

SANTOS, Daniel Leonhardt dos. A territorialidade no contexto da criminalidade global: considerações sobre a influência do ciberespaço na delimitação jurisdicional. Revista Brasileira de Direito Processual Penal, Porto Alegre, vol. 5, n. 2, p. 597-622, mai./ago. 2019. https://doi.org/10.22197/rbdpp.v5i2.235



Esta obra está licenciada com uma Licença Creative Commons Atribuição-NãoComercial 4.0 Internacional. 